\title{
STUDY ON GARDENIA FLORIDA L. (FRUCTUS GARDENIAE) AS A REMEDY FOR ICTERUS
}

\author{
REPORT IV \\ ON THE EFFECT OF THE ACTIVE PRINCIPLE AND EXTRACT OF \\ FRUCTUS GARDENIAE ON THE BILE SECRETION OF \\ RABBITS, BLOOD BILIRUBIN AND PERIPHERAL \\ LYMPH BILIRUBIN OF COMMON BILE-DUCT \\ LIGATED RABBITS
}

\section{TOJI MIWA}

Department of Pharmacology, Faculty of Medicine, Gifu Prefectural University, Gifu Received for publication, May 31, 1954

\section{INTRODUCTION}

In the first paper of this series (1), it was shown that the aqueous and alcoholic extracts of the fruits of Gardenia florida $L$. increased bile-secretion in rabbits; in the second report (2), that the alcoholic extract inhibited the appearance of blood bilirubin when in jected into the aural vein of rabbits whose common bile-duct had been ligated; and in the third report (3), that the same alcoholic extract suppressed the bilirubin in peripheral lymph of rabbits. The present series of experiments were carried out in order to extract the component of the fruit of Gardenia florida $L$. and to find out its effect on the amount of bile-secretion, blood bilirubin and peripheral lymph bilirubin.

\section{Component of Fructus Gardeniae}

As for the component, especially the pigment, contained in the fruit of Gardenia florida, Orth (4) extracted an amorphous pigment from Chinese gardenia, Stenhouse (5) extracted a crystalline pigment from the Indian variety, Gardenia lucida (Roxb.), which he designated, gardenin, and made detailed studies of this pigment in cooperation with Groves $\left(6\right.$, determining its formula as $\mathrm{C}_{14} \mathrm{H}_{12} \mathrm{O}_{6}$. Rochleder and Mayer (7), studied the pigment of Gardenia grandiflora Lour and, from the fact that the various reactions of this pigment were identical with those of saffron pigment, concluded that the two were the same, and designated the pigment crocin. They said that the acid hydrolysis of crocin yielded a sugar and a substance they designated crocetin.

According to Decker (8), Kuhn (9), and Munesada (10), the fru't of Gardenia florida contains a kind of glycoside, crocin, whose hydrolysis yields crocetin, glucose, and a yolatile oil. These workers preparcd ammonium, potassium, and sodium salts, and 
bromo and acetyl derivatives, of crocetin, from which the composition of crocetin was forwarded as $\mathrm{C}_{10} \mathrm{H}_{13} \mathrm{O} \cdot \mathrm{OH}$. Iater, Munssada (10) reexamined this pigment and reported that crocetin, a pigment from saffron, and crocetin, a pigment from Gardenia fruit, were identical from chemical confirmation.

On the other hand, crocin and crocetin were found to belong to the carotenoid pigments, i.e. crocin is the digentiobioside of $\alpha$-crocetin.

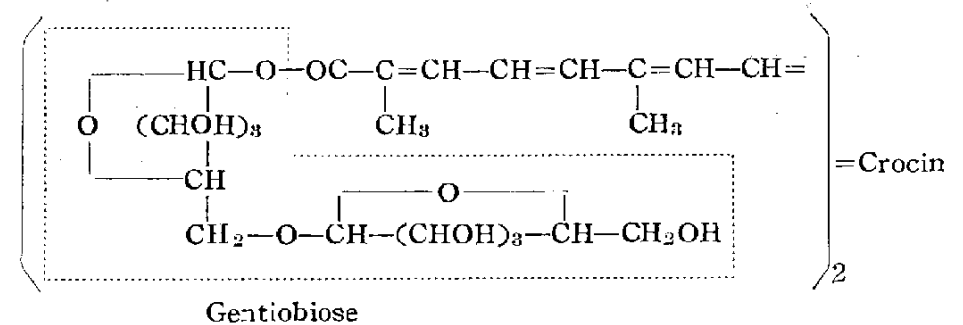

Crocin and crocetin were therefore extracted from the fruit of Gardenia florida $L$., according to the method of Decker (8) and of Munesada (10), with slight modifications deviced by the writer. Since crocetin is insoluble in water, its sodium salt was prepared to submit for pharmacological tests.

Market product of dried Fructus Gardeniae was finely cut and digested with about two volumes of water for 48 hours. This extraction was repeated three times and the combined extract was evaporated on a water bath until syrupy. Fat was removed by extraction with ether, using Kondo-type automatic extractor. This residue was again evaporated on a water bath until a viscous extract was obtained. Methanol was added to the residue and refluxed on a water bath to extract the pigment. The methanolic solution was passed through a chromatographic column filled with activated alumina. Strongly adsorptive pale yellowish brown substance was absorbed in the upper part while crocin was adsorbed on a lower portion. The column was developed with $90 \%$ methanol by which crocin alone flowed out. The effluent thereby obtained was further purified three times by chmatography. The methanolic solution of crocin was cautiously evaporated on a water bath and crosin was thereby obtained.

Crocin is an orange red pigment of highly hygroscopic nature and becomes syrupy when left in the air and the melting point determination is impossible. It is most easily soluble in water, soluble in alcohol, and sparingly in acetone, but is practically insoluble in ether, chloroform, ethyl acetate, carbon disulnde, and benzene, through such a solvent is coloured yellow or red on immersion. The properties of this substance were identical with those described by Munesada, et al. (10), i.e. the aqueous solution reduced the Fehling's solution and the solution obtained from this aqueous solution by hydrolysis with $2-3 \%$ hydrochloric arid and the precipitate thereby obtained removed by filtration showed a strong reductive action on Fehling's solution. This is the reductive action of gentiobiose formed by the hydrolysis of crocin. When crocin is dissolved in conc, sulfuric acid, orange red solution is obtained which changes on 
slight warming or by standing to indigo purple, a common coloration in carotenoid pigments. Application of potassium permanganate in weak alkaline solution to crocin results in immediate coloration to indigo purple. Paper chromatography of crocin, developed with butanol : acetic acid: water in $4: 1: 2$ ratio gave an R. value of 0.32 0.34. Coloration after development was made by ammoniac silver nitrate solution. The same paper chromatography after hydrolysis with hydrochloric acid gave one spot of Rf. $=0.31$ which strongly reduced ammoniac silver nitrate solution. The substance assumed to be crocetin failed to move from the spot of application and there was a fluorescent spot at around Rf. $: 0.17$ which showed silver white coloration by the reagent.

To obtain crocetin from crocin, crocin was heated in five volumes of $2-3 \%$ hydrochloric acid on a water bath for 1 hour, with passage of carbon dioxide gas and under stirring, by which dark brown precipitate was formed. During the course of this hydrolysis, oily substance floated on the surface of the liquid and emitted a specific odor but the substance could not be isolated due to the small amount available.

The precipitate was collected by filtration, washed thoroughly with water, and dried. Munesada had extracted this precipitate with ether but it was found that ethyl acetate was a better solvent and the acetate was therefore used for the extraction. Evaporation of ethyl acetate left a blood red substance which was purified repeatedly from ethyl acetate. The substance is comparatively soluble in ethyl acetate and soluble in ether, but almost insoluble in other solvents. It is easily soluble in alkali solutions, forming a deep yellowish red solution. The substance was dissolved in $1 \%$ sodium hydroxide solution, filtered, and the filtrate was acidified with hydrochloric acid, collecting the precipitate thereby formed by filtration. This procedure was repeated twice and the precipitate was dissolved in as small amount as possible of $1 \%$ sodium hydroxide solution. By allowing the solution to stand after the addition of a large amount of absolute alcohol, sodium salt of crocetin precipitated which was collected by filtration and purified from $30 \%$ alcohol.

\section{Observations on the general symptoms and lethal dose of crocin and crocetin sodium}

\section{1) Subcutaneous injection of crocin in mouse}

By subcutaneous injection of crocin solution in mouse of 14-17 g. body weight, at around lethal dosage, respiration becomes somewhat fast after 10 minutes or so, the movement generally becomes sluggish, and the mouse stays crouched, not walking spontaneous. The animal moves if given external stimulation but the manner of walking is not normal, the hind legs being extended outside and the walking is clumsy. When the symptom is allowed to develop, the eyes are closed and respiration becomes faster, although the animal does move sluggishly if marle to walk. At this stage, the animal will return to the normal abdominal position when placed on its back. As death approaches, respixation bccomes fast and the animal jumps from time to time, but respiration stops and dcath resuits. Autopsy immediately after ceasure of respira- 
tion showed that the heart has stopped in a diastolic state. Ganerally speaking, subcutaneous injection results in death within 24 hours. When the dosag a used is below lethal dose and the animal has escaped death, the sluggishness of the movement and loss of spontaneous movement are observed but the animal recovers gradually and there is hardly any perceptible change after 24 hours.

TABLE 1. Toxicity test of crocin by subcutaneous injection in mouse (14-17g. body weight)

\begin{tabular}{|c|c|c|c|c|c|c|}
\hline $\begin{array}{c}\text { Dose } \\
\text { pro } 10 \mathrm{~g} .\end{array}$ & \multicolumn{5}{|c|}{ Duration until death } & Death rate \\
\hline 0.05 & Alive & Alive & A live & Alive & Alive & $0 / 5$ \\
\hline 0.1 & $\begin{array}{c}\text { Dead } \\
(12 \mathrm{~h}-20 \mathrm{~h})\end{array}$ & $\begin{array}{c}\text { Dead } \\
(1 \mathrm{~h} 30 \mathrm{~m})\end{array}$ & Alive & Alive & $\underset{(12 h-20 h)}{\text { Dead }}$ & $3 / 5$ \\
\hline 0.15 & $\begin{array}{c}\text { Dead } \\
(45 \mathrm{~m})\end{array}$ & $\underset{(5 h 48 \mathrm{~m})}{\text { Dead }}$ & $\underset{(48 m)}{\text { Dead }}$ & $\begin{array}{c}\text { Dead } \\
(1 \mathrm{~h} 35 \mathrm{~m})\end{array}$ & $\begin{array}{l}\text { Dead } \\
(22 m)\end{array}$ & $5 / 5$ \\
\hline
\end{tabular}

As shown is Table 1, toxicity by subcutaneous injection was tested in mice and at $0.05 \mathrm{~g} .10 \mathrm{~g}$. body weight, all remained alive, at $0.1 \mathrm{~g} .10 \mathrm{~g}$., 3 out of 5 died, while at $0.15 \mathrm{~g} .10 \mathrm{~g}$. all animals died. The duration of life, at above lethal dose, was 22 minutes in one case, 45-95 minutes in 3 cases, and 5 hours and 48 minutes in one case.

\section{2) Subcutaneous injection of crocetin sodium in mouse}

Subcutaneous injection of crocetin sodium solution in mouse of 14-17 g. body weight, at around lethal dosage, the same sluggishness of movement as in the case of crocin occurs after about 10 minutes, and the animal remains crouched, not walking spontaneously. At first, the animal reacts to external stimulation but the response becomes very slow after 1-2 hours. The animal does walk when given outside stimulation but the movement is sulggish. When death approaches, the respiration becomes fast, then ceases altogether, resulting in death. With subcutaneous injection, death occurred within 24 hours in 7 out of 8 cases and one case died within 48 hours, but the duration of life is never longer than that. When the dosage was below the lethal dose and the animal escaped death, the movement bacame generally sluggish, the animal remained crouched, and did not walk, but inally took a turn for recovery and there was no outward change after 24 hours.

TABLE 2. Toxicity test of crocetin sodium by subcutaneous injection in mouse (14-17g. body weight)

\begin{tabular}{|c|c|c|c|c|c|c|}
\hline $\begin{array}{c}\text { Dose } \\
\text { pro } 10 \mathrm{~g}\end{array}$ & & \multicolumn{3}{|c|}{ Duration until death } & & Death rate \\
\hline 0.01 & Alive & Alive & Alive & Alive & Alive & $0 / 5$ \\
\hline 0.02 & $\begin{array}{c}\text { Dead } \\
(19 h-20 h)\end{array}$ & Alive & Alive & $\begin{array}{c}\text { Dead } \\
(12 \mathrm{~h}-20 \mathrm{~h})\end{array}$ & $\begin{array}{c}\text { Dead } \\
(22 \mathrm{~h} 48 \mathrm{~m})\end{array}$ & $3 / 5$ \\
\hline 0.05 & $\begin{array}{c}\text { Dead } \\
(13 \mathrm{~h}-22 \mathrm{~h})\end{array}$ & $\begin{array}{c}\text { Dead } \\
(47 \mathrm{~h} 30 \mathrm{~m})\end{array}$ & $\begin{array}{c}\text { Dead } \\
(13 h-22 h)\end{array}$ & $\begin{array}{l}\text { Dead } \\
(13 h)\end{array}$ & $\begin{array}{c}\text { Dead } \\
(8 \mathrm{~h} 34 \mathrm{~m})\end{array}$ & $5 / 5$ \\
\hline
\end{tabular}


The toxicity by subcutaneous injection is shown in Table 2 . By injection of 0.01 g. $10 \mathrm{~g}$. body weight, all the animals survived, with $0.02 \mathrm{~g}$., 3 out of 5 cases died, and with $0.05 \mathrm{~g}$. all the animals died. Above accurate lethal dose, 4 out of 5 cases died within 24 hours, and 1 case within 48 hours.

\section{Effect of crocin and crocetin sodium on the amount of rabbit bile-secretion}

\section{MATERIALS AND METHODS}

For the experimental animal, healthy rabbit of around $2 \mathrm{~kg}$. body weight was used. A definite amount of crocin and crocetin sodium, extracted from the fruit of Gardenia florida $L$. as described earlier, were administered and the amount of bilesecretion was measured by the common bile-duct fistula method of Bürker (11), effluent bile being collected in fractions.

\section{RESULTS}

1) Amount of bile-secretion by injection of $5 \mathrm{cc}$. physiological saline solution into aural vein

As a control, $5 \mathrm{cc}$. of physiological saline solution was injected into the aural vein of a normal rabbit and the amount of bile secreted was measured when injection was given 1 hour after the start of the experiment. The results (1) are shown in Table 3. The amount of bile secreted during every 15 minutes was an average of $2.9 \mathrm{cc}$. at first, decreased gradually, and was $1.1 \mathrm{cc}$. after 5 hours. Comparison of the amount secreted during 1 hour before and after injection by percentage, taking the value before injection as $100 \%$, gave the values of $83.2 \%$ after 1 hour, $72.0 \%$ after 2 hours, $59.8 \%$ after 3 hours, and $48.6 \%$ after 4 hours. There was no significant difference in the amount of bile-secretion in normal, rabbit (1) and that reciving injcction of $5 \mathrm{cc}$. of physiological saline solution in the aural vein.

\section{2) Amount of bile-secretion by injection of crocin into aural vein}

Crocin, at a rate of $0.1 \mathrm{~g} \cdot \mathrm{kg}$. rabbit weight, was dissolved in $5 \mathrm{cc}$. of physiological saline solution, injected into aural vein 1 hour after the start of the experiment, and the amount of bile secreted was measured. The results are shown in Table 4.

Comparison of the amount secreted during 1 hour before and after injection by percentage, taking the value before injection as $100 \%$, gave the values of $100 \%$ after 1 hour, $89.0 \%$ after 2 hours, $70.7 \%$ after 3 hours, and $62.2 \%$ after 4 hours. It may be concluded that the injection of crocin increases the amount of bile-secretion one hour or more after injection.

3) Amount of bile-secretion by injection of crocetin sodium into aural vein

Crocetin sodium, at a rate of $0.01 \mathrm{~g}$. per $\mathrm{kg}$. rabbit weight, was dissolved in $5 \mathrm{cc}$. of physiological saline solution, injected into aural vein 1 hour after the start of the experiment, and the amount of bile secreted was measured, 

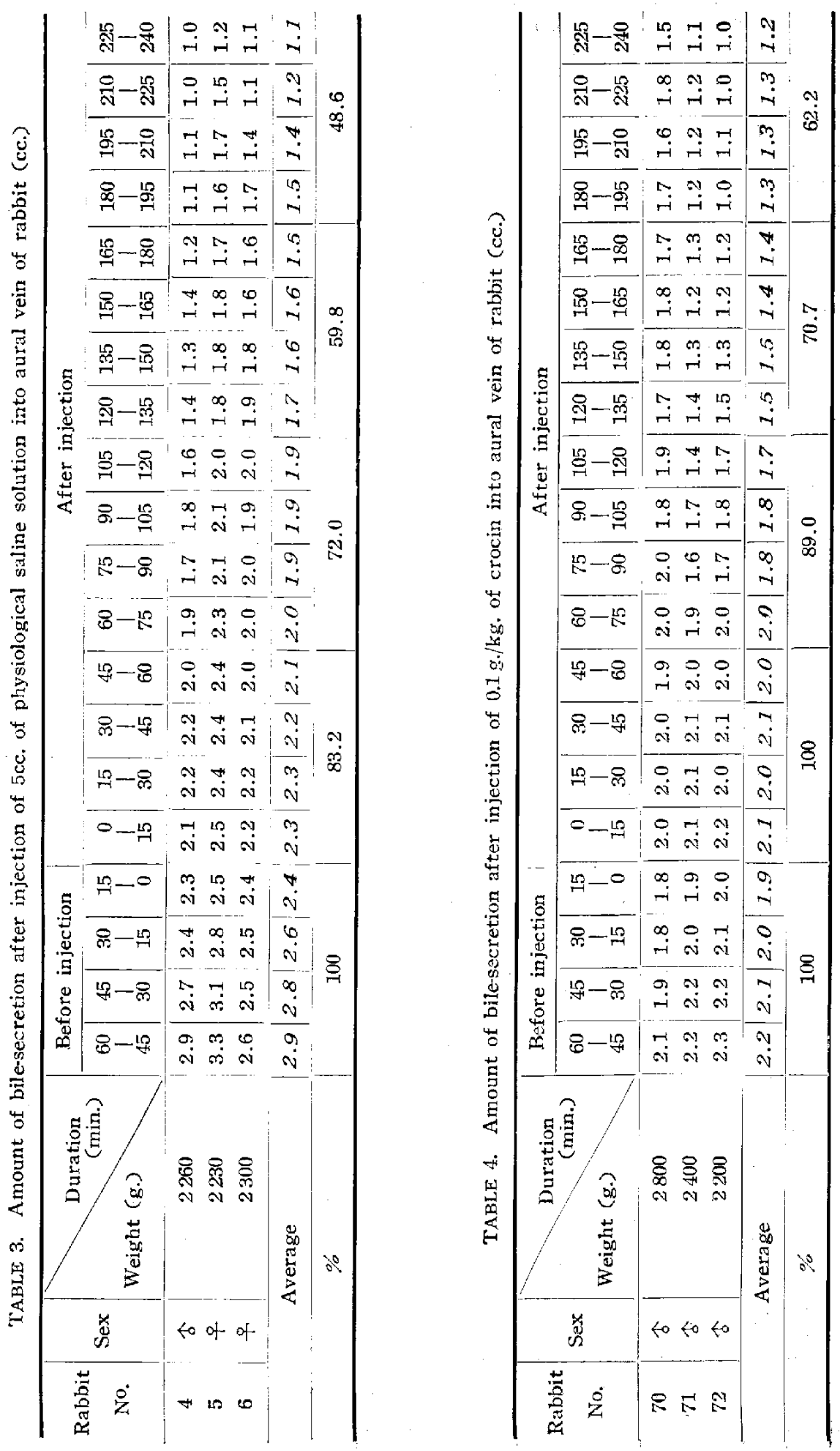


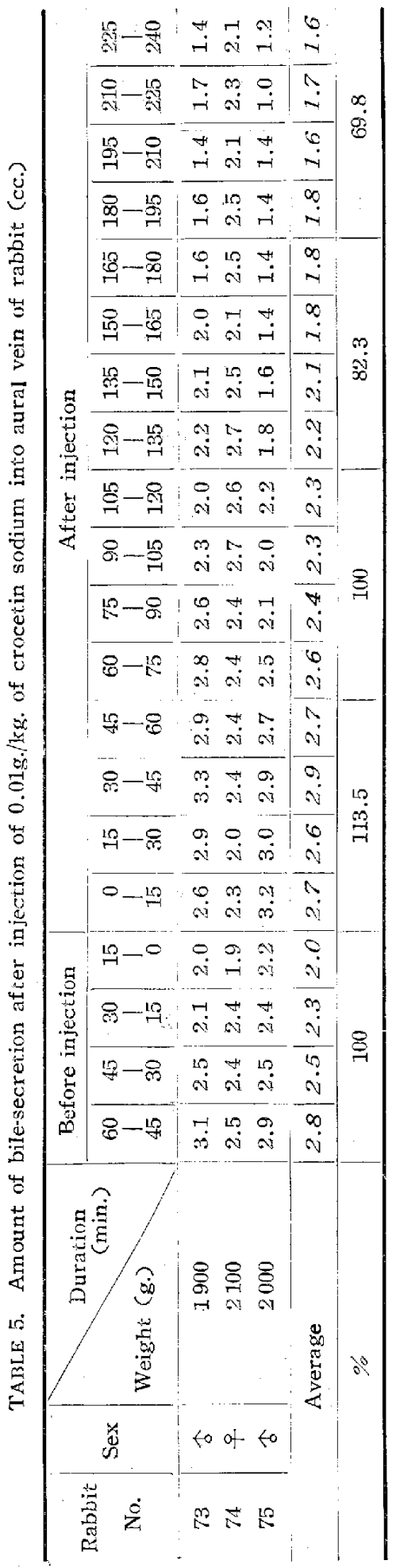

As shown in Table 5, the values obtained, against $100 \%$ before injection, were $113.5 \%$ after 1 hour, $100 \%$ after 2 hours, $82.3 \%$ after 3 hours, and $69.8 \%$ after 4 hours. It is concluded that the injection of crocetin sodium increases the bile secretion for one hour or more after injection.

\section{Effect of crocin and crocetin sodium on the amount of blood bilirubin in common bile- duct-ligated rabbil}

\section{MATERIALS AND METHODS}

Common bile-duct of healthy white rabbit was ligated, blood was drawn from the cervical artery $1,2,3,4,5,6,24$, and 48 hours later, and the amount of bilirubin in blood was measured. However, eight drawings of blood in one rabbit would results in death and, therefore, blood was drawn 24 and 48 hours later from a different rabbit... The determination of blood bilirubin followed the Araki method (12), which is a modification of the method of Jendrassik and Cleghorn (13), and of Jendrassik and Grof (14), using the Pulfrich photometer with S. 53 filter.

\section{RESULTS}

1) Amount of blood bilinibin after injection of 5 cc. of physiological saline solution into the aural vein

As a control, common bile-duct of a rabbit was ligated, 5 cc. of physiological saline solution was injected into the aural vein 1 hour after ligation, and the amount of bilirubin was measured in blood drawn from the cervical artery 1 , $2,3,4,5,6,24$, and 48 hours after ligation. The results (2) are shown in Tables 6 and 7.

The blood bilirubin was in an average of $0.13 \mathrm{mg} . \%$ before ligation of the common bileduct while the average values were $0.17 \mathrm{mg} \%$ after 1 hour, $0.31 \mathrm{mg} \%$ after 2 hours, $0.44 \mathrm{mg} \%$ 
TABLE 6. Amount of blood bilirubin in rabbit with common bile-duct ligated, after intravenous injection of $5 \mathrm{cc}$. physiological salt solution (mg\%)

\begin{tabular}{|c|c|c|c|c|c|c|c|c|c|}
\hline \multirow{3}{*}{$\begin{array}{l}\text { Rabbit } \\
\text { No. }\end{array}$} & \multirow{3}{*}{ Sex } & \multirow{3}{*}{$\begin{array}{r}\text { Elapsed time } \\
\text { (hrs.) } \\
\text { Weight (g.) }\end{array}$} & \multicolumn{2}{|c|}{ Before injection } & \multicolumn{5}{|c|}{ Afier injection } \\
\hline & & & \multirow{2}{*}{$\begin{array}{c}\text { Before } \\
\text { ligature }\end{array}$} & \multicolumn{6}{|c|}{ After ligature } \\
\hline & & & & 1 & 2 & 3 & 4 & 5 & 6 \\
\hline 25 & $\delta$ & 2000 & 0.08 & 0.13 & 0.22 & 0.42 & 0.67 & 1.45 & 1.64 \\
\hline 26 & 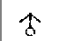 & 2200 & 0.16 & 0.20 & 0.37 & 0.46 & 0.74 & 1.10 & 1.69 \\
\hline 27 & 5 & 2000 & 0.15 & 0.18 & 0.33 & 0.45 & 0.90 & 1.19 & 1.59 \\
\hline \multicolumn{3}{|r|}{ Average } & 0.13 & 0.77 & 0.31 & 0.44 & 0.77 & 7.25 & 1.64 \\
\hline
\end{tabular}

TABLE 7. Amount of blood bilirubin in rabbit with common bile-duct ligated, after intravenous injection of $5 \mathrm{cc}$. physiological salt solution (mg\%)

\begin{tabular}{|c|c|c|c|c|c|}
\hline \multirow{2}{*}{$\begin{array}{c}\text { Rabbit } \\
\text { No. }\end{array}$} & \multirow{2}{*}{ Sex } & \multirow{2}{*}{ Weight (g.) } & \multirow{2}{*}{$\begin{array}{l}\text { Before } \\
\text { ligature }\end{array}$} & \multicolumn{2}{|c|}{ After ligature } \\
\hline & & & & 24 & 48 \\
\hline 28 & $\hat{b}$ & 2200 & 0.17 & 3.17 & 5.14 \\
\hline 29 & $\hat{\Delta}$ & 2200 & 0.11 & 3.93 & 5.70 \\
\hline 30 & $\hat{\alpha}$ & 2000 & 0.13 & 3.68 & 5.20 \\
\hline \multicolumn{3}{|r|}{ Average } & 0.14 & 3.59 & 5.35 \\
\hline
\end{tabular}

after 3 hours, $0.77 \mathrm{mg} \%$ after 4 hours, $1.25 \mathrm{mg} \%$ after 5 hours, $1.64 \mathrm{mg} \%$ after 6 hours, $3.59 \mathrm{mg} \%$ after 24 hours, and $5.35 \mathrm{mg} \% \%$ after 48 hours, showing that the amount increased in the course of time. There was no signinicant difference in the amount of blood bilirubin between common bile-duct-ligated rabbit (2) and that injected with $5 \mathrm{cc}$. of physiological saline solution in aural vein.

2) Amount of blood bilirubin in common bile-duct-ligated rabbit after injection of crocin into aural vein

In a rabbit whose common bile-duct had been ligated, $0.1 \mathrm{~g}$. per $\mathrm{kg}$. body weight of crocin dissolved in $5 \mathrm{cc}$. of physiological saline solution was injected into its aural

IABLE 8. Amount of blood bilirubin after injection of $0.1 \mathrm{~g} . / \mathrm{kg}$. of crocin in common bile-duct-ligated rabbit (mg\%)

\begin{tabular}{|c|c|c|c|c|c|c|c|c|c|}
\hline \multirow{3}{*}{$\begin{array}{c}\text { Rabbit } \\
\text { No. }\end{array}$} & \multirow{3}{*}{ Sex } & \multirow{3}{*}{ Weight (g.) } & \multicolumn{2}{|c|}{ Before injection } & \multicolumn{5}{|c|}{ After injection } \\
\hline & & & \multirow{2}{*}{$\begin{array}{l}\text { Before } \\
\text { ligature }\end{array}$} & \multicolumn{6}{|c|}{ After ligature } \\
\hline & & & & 1 & 2 & 3 & 4 & 5 & 6 \\
\hline 76 & $\hat{o}$ & 2200 & 0.20 & 0.30 & 0.87 & 1.11 & 1.21 & 1.28 & 1.40 \\
\hline 77 & $\hat{o}$ & 2400 & 0.22 & 0.35 & 0.93 & 1.09 & 1.25 & 1.38 & 1.47 . \\
\hline 78 & $\hat{\sigma}$ & 2500 & 0.30 & 0.40 & 0.58 & 0.93 & 1.14 & 1.22 & 1.31 \\
\hline \multicolumn{3}{|r|}{ Average } & 0.24 & 0.35 & 0.79 & 1.04 & 7.20 & 1.29 & 1.39 \\
\hline
\end{tabular}


vein, and the amount of bilirubin in blood was measured. The results obtained are shown in Table 8 and 9.

TABLE 9. Amount of blood bilirubin after injection of $0.1 \mathrm{~g} . / \mathrm{kg}$. of crocin in common bile-duct-ligated rabbit (mg.\%)

\begin{tabular}{|c|c|c|c|c|c|}
\hline \multirow{2}{*}{$\begin{array}{c}\text { Rabbit } \\
\text { No. }\end{array}$} & \multirow{2}{*}{ Sex } & \multirow{2}{*}{$\underbrace{\text { Elapsed time }}_{\text {Weight (g.) }}$} & \multirow{2}{*}{$\begin{array}{r}\text { Bzfore } \\
\text { ligature }\end{array}$} & \multicolumn{2}{|c|}{ After ligature } \\
\hline & & & & 24 & 48 \\
\hline 79 & s & 1900 & 0.21 & 2.86 & 3.62 \\
\hline 80 & 占 & 2200 & 0.35 & 2.35 & 2.98 \\
\hline 81 & 今 & 1907 & 0.19 & 2.61 & 3.24 \\
\hline \multicolumn{3}{|r|}{ Average } & 0.2 .5 & 2.60 & 3.28 \\
\hline
\end{tabular}

The amount of bilirubin bafore ligation was in an avarags of $0.24 \mathrm{mg} \%$ while the average values were $0.35 \mathrm{mg} \% \%$ after 1 hour, $0.73 \mathrm{mg} \%$ after 2 hours, $1.04 \mathrm{mg} \%$ after 3 hours, $1.20 \mathrm{mg} \%$ after 4 hours, $1.29 \mathrm{mg} \% \%$ after 5 hours, $1.39 \mathrm{mg} \% \%$ after 6 hours, $2.60 \mathrm{mg} \%$ after 24 hours, and $3.28 \mathrm{mg} \% \%$ after 49 hours. The values were slightly larger than that of the control after the injection bat smallar after 5 hours, the amount being extremely smaller at 24 and 48 hours after injection. In other words, injection of crocin into aural vein resulted in the suppression of the appearance of blood bilirubin in rabbit whose common bile-duct had been ligated.

3) Amount of bload bilirubin in common bile-duct-ligated rabbil afler injection of crocetin sodium into aural vein

In a rabbit whose common bile-duct had been ligated, $0.01 \mathrm{~g}$. per $\mathrm{kg}$. body weight of crocetin sodium dissolved in $5 \mathrm{cc}$. of physiological saline solution was injected into aural vein 1 hour after ligation and the amount of blood bilirubin was measured. Results obtained are shown in Tables 10 and 11.

TABle 10. Amounc of blood bilirubin af er injection of $0.01 \mathrm{~g} . / \mathrm{kg}$. of croce sodium in common bile-duct-ligated rabbit (mg.\%)

\begin{tabular}{|c|c|c|c|c|c|c|c|c|c|}
\hline \multirow{3}{*}{$\begin{array}{c}\text { Rabbit } \\
\text { No. }\end{array}$} & \multirow{3}{*}{ Sex } & \multirow{3}{*}{ Weight (g.) } & \multicolumn{2}{|c|}{ Befure injection } & \multicolumn{5}{|c|}{ After injection } \\
\hline & & & \multirow{2}{*}{$\begin{array}{l}\text { Befare } \\
\text { lig tcure }\end{array}$} & \multicolumn{6}{|c|}{ After ligature } \\
\hline & & & & 1 & 2 & 3 & 4 & 5 & 6 \\
\hline 82 & $\hat{\sigma}$ & 2000 & 0.25 & 0.41 & 0.58 & 0.89 & 0.99 & 1.09 & 1.20 \\
\hline 83 & $\Im$ & $2 \$ 00$ & 0.15 & 0.47 & 0.56 & 0.63 & 0.71 & 0.83 & 0.96 \\
\hline 84 & $\hat{b}$ & 2400 & 0.23 & 0.46 & 0.65 & 0.75 & 0.78 & 0.90 & 1.13 \\
\hline \multicolumn{3}{|r|}{ Average } & 0.21 & 0.45 & 0.60 & 0.76 & 0.83 & 0.94 & 1.10 \\
\hline
\end{tabular}

The amount of bilirubin byfore ligation was in an average of $0.21 \mathrm{mg} \% \%$ while the values were $0.45 \mathrm{mg} \%$ after 1 hour, $0.5 \mathrm{mg} \%$ aftar $2 \mathrm{hodrs}, 0.7 \mathrm{mg} \% \%$ after $3 \mathrm{~h}$. $1 \mathrm{fs}$, 
TABLE 11. Amount of blood bilirubin after injection of $0.01 \mathrm{~g} . / \mathrm{kg}$. of crocetin sodium in common bile-duct-ligated rabbit (mg.\%)

\begin{tabular}{|c|c|c|c|c|c|}
\hline \multirow{2}{*}{$\begin{array}{l}\text { Rabbit } \\
\text { No. }\end{array}$} & \multirow{2}{*}{ Sex } & \multirow{2}{*}{ Weight (g.) } & \multirow{2}{*}{$\begin{array}{r}\text { Before } \\
\text { ligature }\end{array}$} & \multicolumn{2}{|c|}{ After ligature } \\
\hline & & & & 24 & 48 \\
\hline 85 & 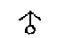 & 2100 & 0.40 & 2.23 & 2.48 \\
\hline 86 & 占 & 2000 & 0.22 & 2.35 & 2.54 \\
\hline 87 & $\uparrow$ & 2100 & 0.18 & 2.11 & 2.73 \\
\hline \multicolumn{3}{|r|}{ Average } & 0.27 & 2.23 & 2.58 \\
\hline
\end{tabular}

$0.83 \mathrm{mg} . \%$ after 4 hours, $0.94 \mathrm{mg} \% \%$ after 5 hours, $1.10 \mathrm{mg} . \%$ after 6 hours, $2.23 \mathrm{mg} \%$ after 24 hours, and $2.58 \mathrm{mg} . \%$ after 48 hours. Compared to that of the control, the value was slightly larger for 3 hours after injection, but smaller $4-5$ hours later. At 24 and 48 hours after injections, the values were markedly lower. In other words, injection of crocetin sodium into the aural vein of a rabbit whose common bile-duct had been ligated suppressed appearance of bilirubin in blood.

V. Effect of crocin and crocetin sodium on the amount of bilirubin in peripheral lymph of common bile-duct-ligated rabbit

\section{MATERIALS AND METHODS}

Healthy rabbit of around $2 \mathrm{~kg}$. body weight was used as experimental animal.

Collection of popliteal lymph fluid followed the methods of Funaoka and Tsuji (15) and of Yoshida (16), with a slight modification of the present writer (3). The collection of popliteal lymph fluid was limited to once from one rabbit because collection of two or more times was difficult and any forcible collection would result in the occlusion of blood. Lymph fluid was collected 6, 24, and 48 hours after ligation of common bile-duct and the amount of bilirubin was measured by the Araki method (12) which is a modification of the method of Jendrassik and Cleghorn (13) and of Jendrassik and Grof (14), using the Pulfrich photometer with S. 53 filter. Crocin and crocetin sodium were dissolved $5 \mathrm{cc}$. of physiological saline solution and injected into the aural vein of a rabbit 1 hour after ligation of the common bile-duct.

\section{RESULTS.}

1) Amount of bilimbin in popliteal lymph effuent after injection of 5 cc. of physiological saline solution into ths aural vein of common bile-duct-ligated rabbit

A definite amount of crocin and crocetin sodium were dissolved in $5 \mathrm{cc}$. of physiological saline solution, injected into the aural vein of a rabbit, and the amount of bilirubin in the popliteal lymph effluent was measured. As a control, $5 \mathrm{cc}$. of physiological saline solution alone was injected into the aural vein 1 hour after ligation of the common bile-duct and the amount of bilirubin in popliteal lymph effuent was determined.

The results are shown in Table 12. 
TABLE 12. Amount of bilirubin in the effluent of popliteal lymph gland of common bile-duct-ligated rabbit after injection of $5 \mathrm{cc}$. of physiological saline solution into the aural vein

\begin{tabular}{|c|c|c|c|c|c|}
\hline \multirow{2}{*}{$\begin{array}{c}\text { Time } \\
\text { after } \\
\text { ligation } \\
\text { (hrs.) }\end{array}$} & \multirow{2}{*}{$\begin{array}{c}\text { Rabbit } \\
\text { No. }\end{array}$} & \multirow{2}{*}{ Sex } & \multirow{2}{*}{$\begin{array}{c}\text { Rabbit } \\
\text { weight } \\
\text { (g.) }\end{array}$} & \multicolumn{2}{|c|}{ Amount of bilirubin } \\
\hline & & & & $\begin{array}{l}\text { Individual } \\
(\mathrm{mg} \%)\end{array}$ & $\begin{array}{l}\text { Mein } \\
(\mathrm{mg} \%)\end{array}$ \\
\hline \multirow{3}{*}{6} & 52 & $\hat{o}$ & 2700 & 0.33 & \multirow{3}{*}{0.34} \\
\hline & 53 & $\widehat{\sigma}$ & 2800 & 0.37 & \\
\hline & 54 & $\uparrow$ & 2000 & 0.30 & \\
\hline \multirow{3}{*}{24} & 55 & $\hat{o}$ & 1900 & 2.29 & \multirow{3}{*}{2.10} \\
\hline & 56 & $\hat{\delta}$ & 2100 & 1.99 & \\
\hline & 57 & $\hat{b}$ & 2000 & 2.04 & \\
\hline \multirow{3}{*}{.18} & 58 & $\hat{b}$ & 2300 & 2.98 & \multirow{3}{*}{2.96} \\
\hline & 59 & 우 & 2000 & 2.79 & \\
\hline & 60 & 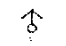 & 2250 & 3.11 & \\
\hline
\end{tabular}

As shown in the table, the amount of bilirubin in the popliteal lymph effluent from the common bile-duct-ligated rabbit (3) was not significantly changed by the injection of $5 \mathrm{cc}$. of physiological saline solution into its aural vein.

2) Amount of bitirubin in posliteal lymph effuent after injection of crocin into aural vein of common bile-duct-ligated rabbit

Crocin, at the rate of $0.1 \mathrm{~g}$. per $\mathrm{kg}$. rabbit body weight, was dissolved in $5 \mathrm{cc}$. of physiological saline solution, injected into the aural vein 1 hour after ligation of the common bile-duct, and the amount of bilirubin in the popliteal lymph effuent was measured. The results are shown in Table 13.

TABLE 13. Amount of bilirubin in popliteal lymph effluent after injection of $0.1 \mathrm{~g} . / \mathrm{kg}$. of crocin in common bile-duct-ligated rabbit

\begin{tabular}{|c|c|c|c|c|c|}
\hline \multirow{2}{*}{$\begin{array}{l}\text { 'Time } \\
\text { tit fier } \\
\text { liglion } \\
\text { (brs.) }\end{array}$} & \multirow{2}{*}{$\begin{array}{c}\text { Rabbit } \\
\text { No. }\end{array}$} & \multirow{2}{*}{ Sex } & \multirow{2}{*}{$\begin{array}{c}\text { Rabbit } \\
\text { weight } \\
\quad(g .)\end{array}$} & \multicolumn{2}{|c|}{ Amount of bilirubin } \\
\hline & & & & $\begin{array}{c}\text { Individual } \\
(\mathrm{mg} \%)\end{array}$ & $\underset{(\mathrm{mg} .0 \%)}{\operatorname{Mean}}$ \\
\hline \multirow{3}{*}{6} & 88 & 古 & 2300 & 0.22 & \\
\hline & 89 & 今 & 2300 & 0.24 & 0.24 \\
\hline & 90 & $\hat{b}$ & 2100 & 0.25 & \\
\hline \multirow{3}{*}{24} & 91 & $\hat{s}$ & 2300 & 1.75 & \\
\hline & 92 & $\hat{\sigma}$ & 2200 & 1.47 & 1.59 \\
\hline & 93 & $\uparrow$ & 1800 & 1.54 & \\
\hline \multirow{3}{*}{48} & 94 & $\hat{\delta}$ & 2400 & 2.00 & \\
\hline & 95 & $\hat{b}$ & 2000 & 2.23 & 2.07 \\
\hline & 96 & $\hat{s}$ & 2000 & 1.97 & \\
\hline
\end{tabular}


The average values were $0.24 \mathrm{mg} \% \%$ after 6 hours, $1.59 \mathrm{mg} \%$ after 24 hours, and $2.07 \mathrm{mg} \%$ after 48 hours, showing that the administration of crosin suppressed the amount of bilirubin in peripheral lymph (popliteal lymph) of common bile-duct-ligated rabbit 24 and 48 hours after injection.

3) Amount of bilirubin in posliteal lymph effuent after injection of crocetin solium into aural vein of common bile-duct-ligated rabbit

Crocetin sodium, at the rate of $0.01 \mathrm{~g}$. per $\mathrm{kg}$. body weight, was dissolved in 5 cc. of physiological saline solution, injected into the a'aral vein 1 hour after ligation of the common bilz-duct, and the amount of bilirubin in po liteal ly-nph effuent was measured. The results ostained are shown in Tabla 14.

TABLE 14. Amount of bilirubin in popliceal lymph efflent af ier injac i ga of $0.01 \mathrm{~g} . / \mathrm{kg}$. of crocecin sodium in common bile-Juc-ligated rabbic

\begin{tabular}{|c|c|c|c|c|c|}
\hline \multirow{2}{*}{$\begin{array}{l}\text { Time } \\
\text { after } \\
\text { ligation } \\
\text { (hrs.) }\end{array}$} & \multirow{2}{*}{$\begin{array}{c}\text { Rabbit } \\
\text { No. }\end{array}$} & \multirow{2}{*}{ Sex } & \multirow{2}{*}{$\begin{array}{c}\text { Rabbit } \\
\text { weight } \\
\text { (g.) }\end{array}$} & \multicolumn{2}{|c|}{ Amount of bili rubin } \\
\hline & & & & $\begin{array}{c}\text { Individual } \\
(\operatorname{mg} \%)\end{array}$ & $\begin{array}{l}\text { Me:in } \\
\text { (mg. }\end{array}$ \\
\hline \multirow{3}{*}{6} & 97 & $\hat{b}$ & 2100 & 0.26 & \multirow{3}{*}{0.25} \\
\hline & 98 & $\hat{s}$ & 1900 & 0.23 & \\
\hline & 99 & $\hat{a}$ & 2000 & 0.25 & \\
\hline \multirow{3}{*}{24} & 100 & $\hat{\delta}$ & 2200 & 0.99 & \multirow{3}{*}{1.04} \\
\hline & 101 & $\widehat{s}$ & 2000 & 1.11 & \\
\hline & 102 & $\hat{s}$ & 1800 & 1.02 & \\
\hline \multirow{3}{*}{48} & 103 & 今 & 2600 & 2.23 & \multirow{3}{*}{2.15} \\
\hline & 104 & $\hat{b}$ & 2300 & 2.33 & \\
\hline & 105 & 今 & 2000 & 1.91 & \\
\hline
\end{tabular}

The average values were $0.25 \mathrm{mg} \% \%$ aftər 6 hours, $1.04 \mathrm{mg} \%$ ait 24 hours and $2.15 \mathrm{mg} \%$ after 48 hours. Comparison with the values obtained from the control clearly showed that crocetin sodium suppressed the amount of bilirubin in periphoral lymph (popliteal lymph) in common bile-duct-ligated rabbit 24 and 48 hours after injection.

\section{CONCLUSION}

1. The chief constituents of Fructus Gardeniae, the fruit of Garlenia florida L., were proved to be both the substances, crocin and crocetin.

2. Reliable lethal dose of crosin in mouse is $0.15 \mathrm{~g}$. and that of crosetin sodium, $0.05 \mathrm{~g}$.

3. The amount of bile-secretion in rabbit, after injection of $5 \mathrm{cc}$. of physiological saline solution into its aural vein, gradually decreases in the course of time, as determined by the common bile-duct fistula method of Bürker.

4. Administration of crocin or crocetin sodium results in the increase of bilesecretion for 1 hour or more after injection. 
5. The amount of blood bilirubin in common bile-duct-ligated rabbit after in jection of $5 \mathrm{cc}$. of physiological saline solution into its aural vein, measured every hour after injection, shows that the amount increases in the course of time, average value of $0.17 \mathrm{mg} . \%$ after 1 hour increasing to the average of $1.64 \mathrm{mg} \%$ after 6 hours, 3.59 mg. $\%$ after 24 hours, and $5.35 \mathrm{mg} . \%$ after 48 hours.

6. The amount of blood bilirubin in common bile-duct-ligated rabbit, after injection of crocin or crocetin sodium solution, tends to be slightly larger than that of the control but becomes smaller after 6 hours, and the values at 24 and 48 hours after injection are extremely smaller than those of the control. In other words, crocin and crocetin sodium suppresses the appearance of blood bilirubin in common bile-ductligated rabbit.

7. The amount of bilirubin in peripheral lymph (popliteal lymph) of common bile-duct-ligated rabbit, after injection of $5 \mathrm{cc}$. of physiological saline solution, is in an average of $0.34 \mathrm{mg} \%$ after 6 hours, $2.10 \mathrm{mg} \%$ after 24 hours, and $2.95 \mathrm{mg} \% \%$ after 48 hours.

8. The amount of bilirubin in peripheral lymph (popliteal lymph) of common bileduct-ligated rabbit, after injection of crocin is in average of $0.24 \mathrm{mg}$. 6 after 6 hours, $1.59 \mathrm{mg} \%$ after 24 hours, and $2.07 \mathrm{mg} . \%$ after 48 hours, and the same after injection of crocetin sodium are $0.25 \mathrm{mg} \%$ after 6 hours, $1.04 \mathrm{mg} \%$ after 24 hours, and 2.15 mg.\% after 24 hours, showing clearly that the amount of bilirubin in peripheral lymph (popliteal lymph) in common bile-duct-ligated rabbit is suppressed by injection of crocin or crocetin sodium.

\section{REFERENCES}

1) MiWA, T.: Jap. J. Pharmacol. 2, 102 (1953)

2) MrWA, T.: Ibid. 2, 139 (1953)

3) MIWA, I.: Ibid. 3, I (1953)

4) ORTH, M.V.: Cited from (10)

5) Stenhouse, J.: Ann. 98, 316 (1856)

6) GRoves, E.: Ibid. 200, 323 (1879)

7) Rochleder AND MAYER: Cited from (10)

8) DECKer, F.: Chem. Centr. 2, 962 (1906): Arch. d. Pharm. 252, 139 (1914)

9) KuIrN, R., Winterstein, A. AND WIEGARD, W.: Helv. Chim. 11, 716 (1928)

10) Munesada, T.: Journ. Pharm. Soc. Japan 42, 666 (1922)

11) BÜRKER, K.: Pflügers Arch, 83, 241 (1901)

12) ARAKI, Y.: Sogo Igaku 4, 706 (1947)

13) JENDRASsik, L. AND CLEGHORN, P. A.: Biochem. Zeilschr. 239, 1 (1937)

14) JENDRAssiK, L. AND GRóF, P.: Ibid. 297, 81 (1938)

15) FunAokA, S. AND TSUJI, K.: Arbeiten aus der dritten Abteilung des Andomischen Institutes der Kaiserlichen Universität Kyoio Heft 4, 135 (1934)

16) YoshidA, Y.: Ibid. Heft 5, 83 (1935) 